\title{
ARCHITECTURAL ISSUES OF BUILDING INFORMATION SYSTEMS FOR ELECTRONIC REPORTING OF PUBLIC PROJECTS
}

\author{
R. Kirilov* \\ University of National and World Economy, Sofia, Bulgaria
}

\begin{abstract}
Bulgarian economy is in a state in which it is necessary and important for citizens and businesses to apply and implement a variety of projects co-financed by European Union funds. Over the past few years great experience has been gained from both the business and various non-governmental organizations, and the administrative structures in the approval and reporting of such schemes of financing. Unfortunately, however, still a large part of the operational programs (and this is expected to continue over the next programming period 2014 - 2020) impose and require a paper application and reporting of costs. There are also schemes in which the computerization of administrative processes has advanced significantly and beneficiaries are able to electronically monitor, manage, report and verify their public expenditure. In this direction the paper considers the architectural issues of building of such systems. The paper suggests an architectural model of such a system and formulates conclusions based on this model.
\end{abstract}

Key words: information systems, electronic reporting, projects.

\section{INTRODUCTION}

Project BG051PO001 - 3.3.07-0002 "Students practice" (1) focuses on practical training of students in real working environment. Its ultimate objective is to increase the percentage of students employed on a permanent contract. For the period 06/2013 - 12/2014 University of National and World Economy (2) has concluded the contract of 4200 students for practical training and verified their costs electronically.

\section{ELECTRONIC REPORTING}

Electronic reporting of expenditure on public projects is based on the following principles (Figure 1).

- Complete line between tax and expenditure;

- Correspondence between underlying and reported costs;

- Full correspondence between electronic and scanned documents.

\section{ARCHITECTURAL ISSUES OF BUILDING INFORMATION SYSTEMS}

The architectural features of information systems for electronic reporting projects can be

\footnotetext{
*Correspondence to: Rosen Kirilov, University of National and World Economy, Sofia 1700, tel. +359 28195 312, e-mail: rosenkirilov@mail.bg
}

created on the basis of their life cycle. The following main stages in the development of similar systems can be defined (Figure 2).

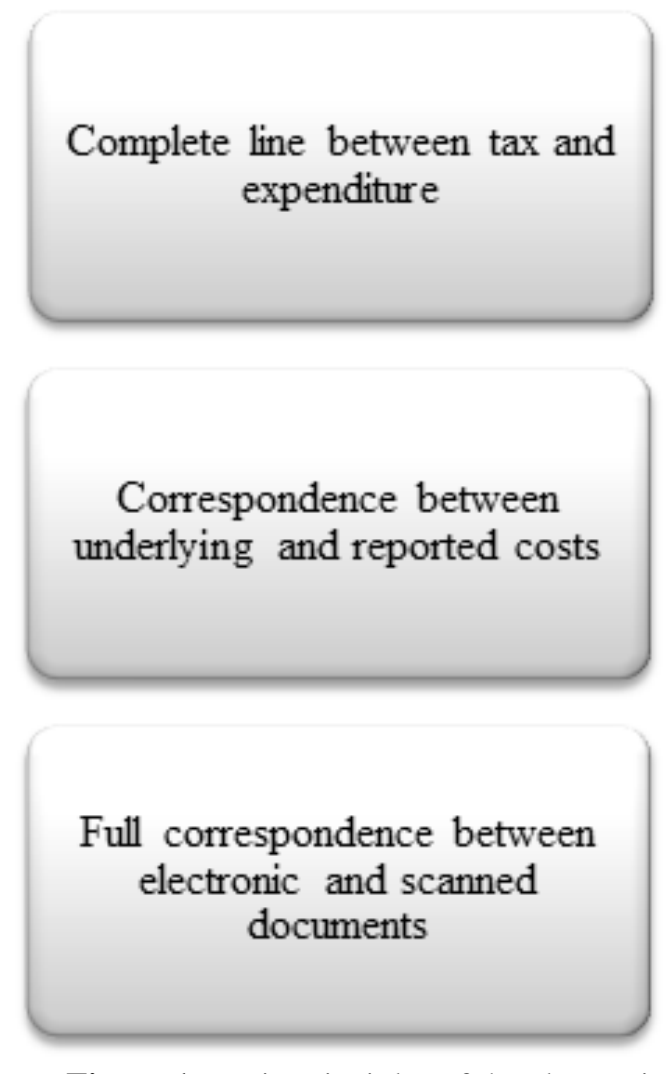

Figure 1. Basic principles of the electronic reporting 


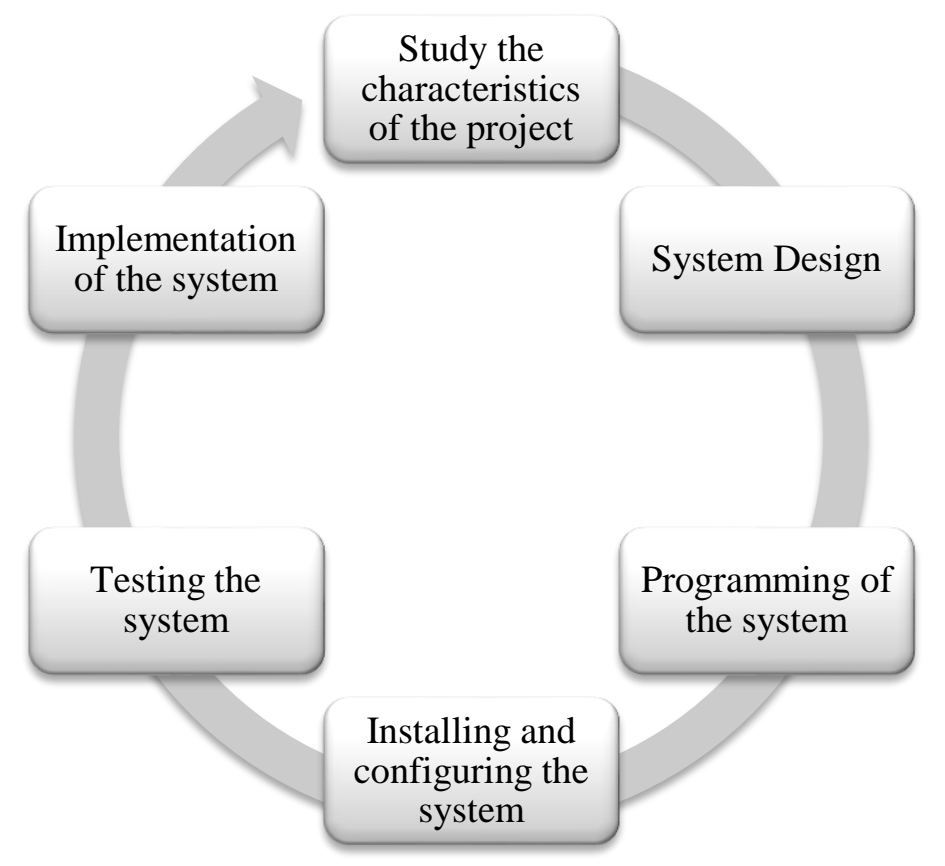

Figure 2. Main stages in the development of similar systems

- Study the characteristics of the project, which includes familiarization with the legislation; study of regulatory restrictions; analysis of target groups; analysis of key business processes; definition of IT problems; formulation of system requirements;

- Design of the system, which includes: the design of the database; designing the user interface for the system; designing business logic; designing queries; design of system links with external systems;

- Programming of the system, which includes: creating a database system with the means chosen for implementation; creation of web design of the system; Implementation of the business logic of the system set work rules; implementation of a records system; Implementation of the system links with external systems;

- Installation and configuration of the system, which includes installation of the server and application software required for correct operation of the system; hosting the webbased system;

- Testing of the system, which includes: establishing procedures for system testing; preparation of control examples; system testing under various load levels;

- Implementation of the system, which includes: preparation of guidelines for working with the system; demonstration of the system; training system.
An essential module of this system is to determine the relevance of the results of the process of reporting. Figure $\mathbf{3}$ shows the architecture of this part of the system.

For proper implementation of information systems for electronic reporting of projects are important the overall performance of the activities from the exploratory stage. It should be done detailed study of the particulars of implementing the project and the beneficiary organization and relevant partners. This information is a key to the successful completion of subsequent stages. When it is mainly carried out planning activities for the entire project for this purpose examine the wishes and needs of the client. Here the main emphasis is unresolved or partially resolved IT problems in the subject area and their impact on management decisions. On this basis, an analysis of existing business processes and draw full specification matrix of features and functionality of the proposed development and implementation of the information system. Of great importance for the successful process of implementation is to determine the degree of consistency and compatibility of the requirements of the client with the proposed functionality of the system and to demonstrate the feasibility of implementation based on the complexity of customer requirements. Specific architecture of server-side applications and detailed description of the needs of public projects in e-government area are illustrated by other authors in their researches $(3,4)$. 


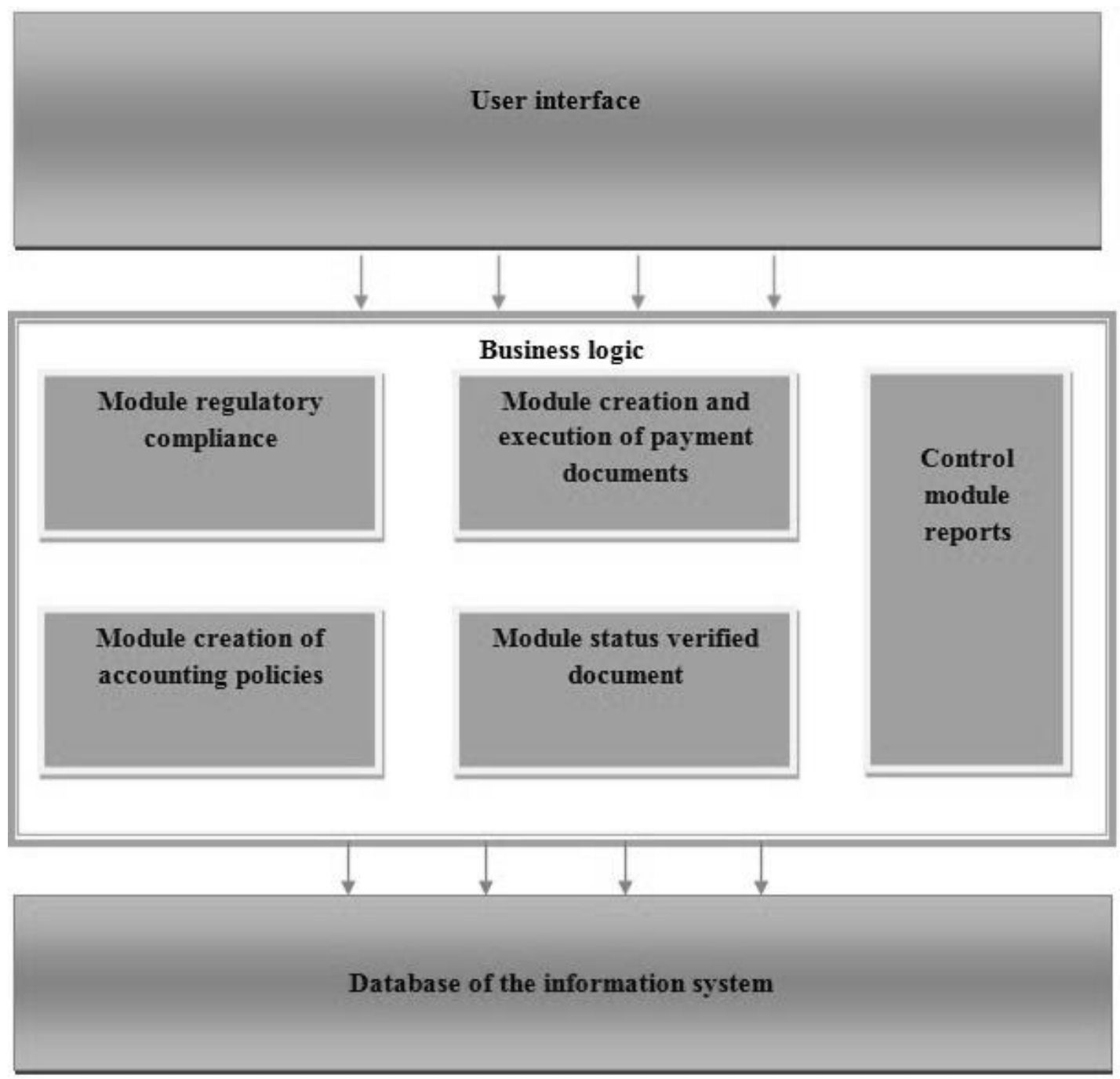

Figure 3. Architecture of the system

\section{CONCLUSIONS}

Finally, it should be noted that the application of this approach is relatively new. As such it has certain disadvantages. Such difficulties are mainly corrections of documents and payments. They are the basis for future development of electronic reporting of expenditure. Prospects in the future are the majority of public projects to be verified in a similar way.

\section{REFERENCES}

1. http://praktiki.mon.bg

2. http://www.unwe.bg

3. Milev P., Advantages of using server-side applications for implementing media monitoring solutions, 4th International Conference on Application of Information and Communication Technology and Statistics in Economy and Education (ICAICTSEE 2014), University of national and world economy, Sofia, 2014.

4. Kirilova K., E-Government, Publishing complex of University of national and world economy, Sofia, 2015. 